\title{
The impact of COPD on health status: findings from the BOLD study
}

\author{
Christer Janson ${ }^{1}$, Guy Marks², Sonia Buist ${ }^{3}$, Louisa Gnatiuc ${ }^{4}$, Thorarinn Gislason $^{5}$, \\ Mary Ann McBurnie ${ }^{6}$, Rune Nielsen7, Michael Studnicka ${ }^{8}$, Brett Toelle?, \\ Bryndis Benediktsdottir ${ }^{5}$ and Peter Burney ${ }^{4}$
}

\begin{abstract}
Affiliations: 'Dept of Medical Sciences, Respiratory Medicine and Allergology, Uppsala University, Uppsala, Sweden. ${ }^{2}$ Dept of Respiratory Medicine, Liverpool Hospital and Woolcock Institute of Medical Research, Sydney, and ${ }^{9}$ Respiratory and Environmental Epidemiology Group, Woolcock Institute of Medical Research, Sydney, Australia. ${ }^{3}$ Oregon Health and Science University, Portland, OR, and ${ }^{6}$ Kaiser Permanente Center for Health Research, Portland, OR, USA. "Respiratory Epidemiology and Public Health, Imperial College London, London, UK. ${ }^{5}$ Faculty of Medicine, University of Iceland and Respiratory Medicine and Sleep, Landspitali University Hospital, Reykjavik, Iceland. ${ }^{7}$ Dept of Thoracic Medicine, Haukeland University Hospital, Bergen, Norway. ${ }^{8}$ Dept of Respiratory Medicine, Paracelsus Medical University, Salzburg, Austria.
\end{abstract}

Correspondence: C. Janson, Dept of Medical Sciences, Uppsala University, Box 256, 75105 Uppsala, Sweden. E-mail: christer.jansonamedsci.uu.se

ABSTRACT The aim of this study was to describe the impact of chronic obstructive pulmonary disease (COPD) on health status in the Burden of Obstructive Lung Disease (BOLD) populations.

We conducted a cross-sectional, general population-based survey in 11985 subjects from 17 countries. We measured spirometric lung function and assessed health status using the Short Form 12 questionnaire. The physical and mental health component scores were calculated.

Subjects with COPD (post-bronchodilator forced expiratory volume in 1 s/forced vital capacity $<0.70$, $\mathrm{n}=2269)$ had lower physical component scores $(44 \pm 10$ versus $48 \pm 10$ units, $\mathrm{p}<0.0001)$ and mental health component scores $(51 \pm 10$ versus $52 \pm 10$ units, $\mathrm{p}=0.005)$ than subjects without COPD. The effect of reported heart disease, hypertension and diabetes on physical health component scores ( -3 to -4 units) was considerably less than the effect of COPD Global Initiative for Chronic Obstructive Lung Disease grade 3 (-8 units) or 4 (-11 units). Dyspnoea was the most important determinant of a low physical and mental health component scores. In addition, lower forced expiratory volume in $1 \mathrm{~s}$, chronic cough, chronic phlegm and the presence of comorbidities were all associated with a lower physical health component score.

COPD is associated with poorer health status but the effect is stronger on the physical than the mental aspects of health status. Severe COPD has a greater negative impact on health status than self-reported cardiovascular disease and diabetes.

@ERSpublications

COPD is related to worse health status: impairment is greater than in self-reported cardiovascular diseases or diabetes http://ow.ly/p1cIx

Received: Sept 272012 | Accepted after revision: Feb 282013 | First published online: May 302013

Support statement: The BOLD initiative has been funded in part by unrestricted educational grants to the Operations Center from ALTANA, Aventis, AstraZeneca, Boehringer-Ingelheim, Chiesi, GlaxoSmithKline, Merck, Novartis, Pfizer, Schering-Plough, Sepracor, and University of Kentucky. The Co-ordination of the BOLD initiative by Imperial College London has been funded by the Wellcome Trust (grant number 085790/Z/08/Z) since December 2008.

Conflict of interest: Disclosures can be found alongside the online version of this article at www.erj.ersjournals.com

Copyright OERS 2013. ERJ Open articles are open access and distributed under the terms of the Creative Commons Attribution Non-Commercial Licence 3.0.

This article was modified in April 2016 to correct errors in the licence information. 


\section{Introduction}

Chronic obstructive pulmonary disease (COPD) is characterised by airflow limitation that is not fully reversible and accelerated decline of lung function. The disease is an important and growing cause of morbidity and mortality worldwide. COPD is expected to be the third leading cause of morbidity and the sixth leading cause of mortality in 2020 [1]. Patients with COPD experience respiratory symptoms and physical incapacity and often have several comorbid conditions. Consequently, they often have impaired health status or health-related quality of life, which in itself is an independent predictor of hospitalisations [2] and mortality [2,3]. Low lung function [4], female sex [5], frequent exacerbations [4, 6], comorbidities [4] and a low level of physical activity [7] have been identified as factors that negatively influence health status in COPD, whereas physical exercise training $[8,9]$ and pharmacological interventions can have a positive effect on health status $[10,11]$. However, the nature of the impact and the factors that influence health status are not well understood.

The major purpose of the Burden of Obstructive Lung Disease (BOLD) study is to estimate the social and economic burden of COPD around the world [12]. The study includes standardised measurement of spirometric lung function and a structured interview that incorporates the Short Form 12 (SF-12) questionnaire [13]. Previous BOLD analyses have concentrated on prevalence [12], risk factors [14] and economic aspects [15] of COPD. However, for the individual patient the major impact of the disease is manifest as deterioration in health status. The aims of the analyses in this paper are to describe the impact of COPD on health status in adults aged $\geqslant 40$ years and to identify determinants of low health status in people with COPD.

\section{Population and methods}

The design and rationale for the BOLD Initiative and preliminary data on prevalence have been published elsewhere [13]. Sampling plans designed to randomly recruit a representative sample of the population were used for the recruitment of participants at all study sites. The present analysis included data from 18 sites in 17 countries for subjects in whom valid spirometry and health status data were obtained. The sites were: Adana (Turkey), Salzburg (Austria), Cape Town (South Africa), Reykjavik (Iceland), Hannover (Germany), Krakow (Poland), Bergen (Norway), Vancouver (Canada), Lexington (USA), Manila (Philippines), Sydney (Australia), London (United Kingdom), Uppsala (Sweden), Mumbai (India), Lisbon (Portugal), Maastricht (the Netherlands), Nampicuan/Talugtug (Philippines) and Tartu (Estonia).

Each participating site aimed to recruit a population-based sample of at least 600 adults (300 males and 300 females) who were not institutionalised, were aged $\geqslant 40$ years, and were living in a well-defined administrative area in which the total population exceeded 150000 . Target recruitment numbers, as well as the sampling plans, were approved in advance by the Operations Center (Portland, OR, USA). Questionnaires were used to obtain information about respiratory symptoms, health status, comorbidities and risk factors for COPD. Pre- and post-bronchodilator spirometry testing was performed. Every site obtained approval from its local ethics committee and written informed consent from each participant.

The study population consisted of 14450 subjects of whom 13495 had recorded health status data and, of these, 11985 subjects performed a technically satisfactory spirometry whereas 1510 did not have a technically satisfactory spirometry recording according to the pre-defined criteria of the BOLD protocol [13].

\section{Spirometry and body mass index}

Lung function data were obtained at all BOLD sites using the ndd EasyOne Spirometer (ndd Medical Technologies, Andover, MA, USA). Lung function was measured before and 15 min after administration of $200 \mu \mathrm{g}$ of salbutamol. All spirograms were reviewed by the BOLD Pulmonary Function Reading Center and assigned a quality score based on acceptability and reproducibility criteria of the American Thoracic Society and European Respiratory Society guidelines [16]. Prediction equations derived from the third US National Health and Nutrition Examination Survey were used to compute predicted forced expiratory volume in $1 \mathrm{~s}$ (FEV1) [17]. Weight and height were measured at the clinic visit by trained technicians and body mass index (BMI) was calculated (weight $(\mathrm{kg}) /(\text { length }(\mathrm{m}))^{2}$ ). The participants were categorised into four groups based on BMI: $<20,20-25,>25-30$ and $>30 \mathrm{~kg} \cdot \mathrm{m}^{-2}$.

\section{Definition and classification of COPD}

COPD was defined according to the Global Initiative for Chronic Obstructive Lung Disease (GOLD) criteria as post-bronchodilator $\mathrm{FEV} 1 /$ forced vital capacity $(\mathrm{FVC})<0.70$ [18]. We also performed sensitivity analyses, defining COPD as post-bronchodilator FEV1/FVC predicted below the lower limit of normal (LLN) [17]. Subjects with COPD and FEV1 $\geqslant 80 \%$ predicted were classified as GOLD grade 1; those with COPD and $\mathrm{FEV}_{1}<80 \%$ but FEV $1 \geqslant 50 \%$ predicted were classified as GOLD grade 2 ; those with COPD and 
FEV $1<50 \%$ but FEV $1 \geqslant 30 \%$ predicted were classified as GOLD grade 3 and those with COPD and FEV1 $<30 \%$ predicted were classified as GOLD grade 4 [18].

\section{Questionnaire data}

Questionnaire data were obtained by face-to-face interviews administered by trained and certified staff in the participant's native language. Standard methods were used for forward and backward translation and reconciliation. All participants completed a core questionnaire, which was based on standardised instruments [13].

\section{Health status}

Health status was assessed by the SF-12 questionnaire (version 2), which is a generic instrument for assessing health status. The instrument was developed from the short form 36 (SF-36) questionnaire developed to catch the mental and physical score of the SF-36 using only 12 questions compared with the 36 questions in the SF-36 instrument. The physical (PCS) and mental health (MCS) component scores were calculated [19], with higher values indicating better health status.

\section{Educational level}

Educational level was calculated in years based on the question: "How many years of schooling have you completed?"

\section{Smoking history}

The participants were categorised as never-, ex- and current smokers. Smoking was defined as $>20$ packs of cigarettes in a lifetime or $>1$ cigarette each day for a year.

\section{Comorbidities}

Heart disease was defined as answering "yes" to the question: "Has a doctor or other healthcare provider ever told you that you had heart disease?". Hypertension, diabetes and stroke were defined in a similar manner.

Dyspnoea was graded using a modification of the Medical Research Council dyspnoea scale [20]. Stage 0 was defined as answering "no" to the question: "Are you troubled by shortness of breath when hurrying on the level or walking up a slight hill?" and stage IV as a positive answer to the question: "Are you too short of breath to leave the house or short of breath on dressing or undressing?"

\section{Symptoms}

The following symptoms were included in the analyses: wheeze: "wheezing or whistling in the chest at any time in the last 12 months"; chronic cough: "cough on most days for as much 3 months each year"; and chronic phlegm: "bringing up phlegm from the chest, having phlegm in the chest that is difficult to bring up on most days for as much as 3 months each year".

\section{Medication}

The level of medication for breathing problems was categorised into four groups based on the participants answer to the questions. "In the past 12 months, have you taken any medications for your breathing?" If the participants answered yes, the name and formulation of the medication was asked for. In the present analyses, medication level 0 was no bronchodilators or inhaled corticosteroids (ICSs); level 1 was shortacting $\beta_{2}$-agonists or ipratropium but no long-acting $\beta_{2}$-agonists (LABAs), tiotropium, theophylline or ICSs; level 2 was LABAs, tiotropium or theophylline but no ICSs; and level 3 was ICSs with or without bronchodilators.

\section{COPD exacerbation}

COPD exacerbation was defined as a reported medical visit for an episode of breathing problems that interfered with usual daily activities in a subject with COPD.

\section{Statistical analysis}

All analyses were performed in STATA software, version intercooled STATA 11 (Stata Corporation, College Station, TX, USA). Differences between subjects with and without COPD were tested by the t-test and Chisquared test. The association between FEV1 and health status in subjects with COPD was evaluated by linear regression. Multiple linear regression was used in the multiple variable analyses with PCS and MCS, respectively, as dependent variables in the whole population and in the subpopulation with COPD. In these analyses, adjustments were made for age, sex, BMI, smoking history and educational level. Regression models were fitted separately for each site and results for the association between health status and COPD were pooled across sites using random effects meta-analysis in order to detect heterogeneity between the 
centres [21]. Heterogeneity was quantified using the $\mathrm{I}^{2}$ statistic [22]. A p-value of $<0.05$ was considered statistically significant.

\section{Results}

The characteristics of the 11985 subjects who had both health status data and a technically satisfactory spirometry, grouped by COPD status, are presented in table 1. Participants with COPD $(n=2269)$ were significantly older, more often male, had a lower BMI, lower educational level and had a higher prevalence of heart disease, hypertension and stroke than those without COPD (table 1).

\section{Sample population}

Participants with COPD had lower PCS $(44 \pm 10$ versus $48 \pm 10$ units, $\mathrm{p}<0.0001)$ and MCS $(51 \pm 10$ versus $52 \pm 10$ units, $\mathrm{p}=0.005)$ than participants without COPD. The severity of COPD was inversely correlated with both these scales (figure 1).

In the multivariate analyses, both PCS and MCS were inversely related to COPD severity (table 2). The strength of the relationship between health status and COPD, as well as other diseases, is presented in figure 2 and table 2. The presence of heart disease, hypertension and diabetes was associated with lower PCS and MCS. Stroke was only significantly related to lower PCS. The effect of these non-COPD diseases on PCS was of approximately the same magnitude as the effect of having COPD GOLD grade 2, but considerably less than the effect of GOLD grade 3 and 4 (fig. 2). The estimated effect of having COPD of any severity was of the same level of magnitude as having self-reported heat disease and diabetes.

The combined effect of COPD severity level and the presence of comorbidities on PCS are presented in figure 3. Having COPD GOLD grade 1 was only associated with lower PCS if the subject also had heart disease, hypertension, diabetes or stroke. Subjects with COPD grade 3 and 4 and any of these comorbidities had the lowest PCS.

Female sex, current smoking and having a BMI $<20 \mathrm{~kg} \cdot \mathrm{m}^{-2}$ were also associated with lower PCS and MCS (table 2). Ex-smoking status, a lower educational level and having a BMI $>30 \mathrm{~kg} \cdot \mathrm{m}^{-2}$ were all associated with a lower PCS. Finally, older age was associated with a lower PCS but a higher MCS.

The random effects meta-analysis estimate of the effect of having COPD grade 2 and higher was a PCS that was mean (95\% confidence interval) 4.3 (3.6-4.9) units lower (fig. 4). There was no significant betweencentre heterogeneity in the association between PCS and GOLD grade 2+ (fig. 4). Having COPD was associated with a $1.8(0.8-2.8)$ units lower MCS (fig. 5). There was significant and large between-centre heterogeneity in the association between MCS and GOLD grade 2+ (fig. 5). This heterogeneity was largely explained by a stronger association between COPD grade $2+$ and MCS in Mumbai, India. With Mumbai

TABLE 1 Characteristics of the participants according to severity of airflow limitation grouped by Global Initiative for Chronic Obstructive Lung Disease grade

\begin{tabular}{|c|c|c|c|c|c|c|}
\hline & No COPD & Grade 1 & Grade 2 & Grade 3 & Grade 4 & p-value \\
\hline Subjects $n$ & 9716 & 1027 & 945 & 257 & 40 & \\
\hline Age years & $55.2 \pm 10.8$ & $64.9 \pm 12.2$ & $64.0 \pm 11.2$ & $63.4 \pm 11.7$ & $60.1 \pm 9.9$ & $<0.0001$ \\
\hline $\begin{array}{l}\text { Years of education } \\
\text { Smoking history }\end{array}$ & $11 \pm 5$ & $11 \pm 4$ & $10 \pm 4$ & $9 \pm 4$ & $8 \pm 4$ & $\begin{array}{l}<0.0001 \\
<0.0001\end{array}$ \\
\hline Never-smoker & 49.3 & 33.8 & 27.7 & 19.5 & 22.5 & \\
\hline Body mass index $\mathrm{kg} \cdot \mathrm{m}^{-2}$ & & & & & & $<0.0001$ \\
\hline$<20$ & 5.9 & 4.8 & 14.2 & 28.0 & 47.5 & \\
\hline $20-25$ & 31.8 & 35.3 & 29.6 & 27.6 & 37.5 & \\
\hline$>25-30$ & 38.0 & 42.3 & 32.9 & 25.2 & 12.5 & \\
\hline$>30$ & 24.4 & 17.6 & 23.3 & 19.3 & 2.5 & \\
\hline \multicolumn{7}{|l|}{ Comorbidities } \\
\hline
\end{tabular}

Data are presented as $\%$ or mean \pm SD, unless otherwise stated. COPD: chronic obstructive pulmonary disease. ${ }^{\#}$ : no COPD versus COPD. 


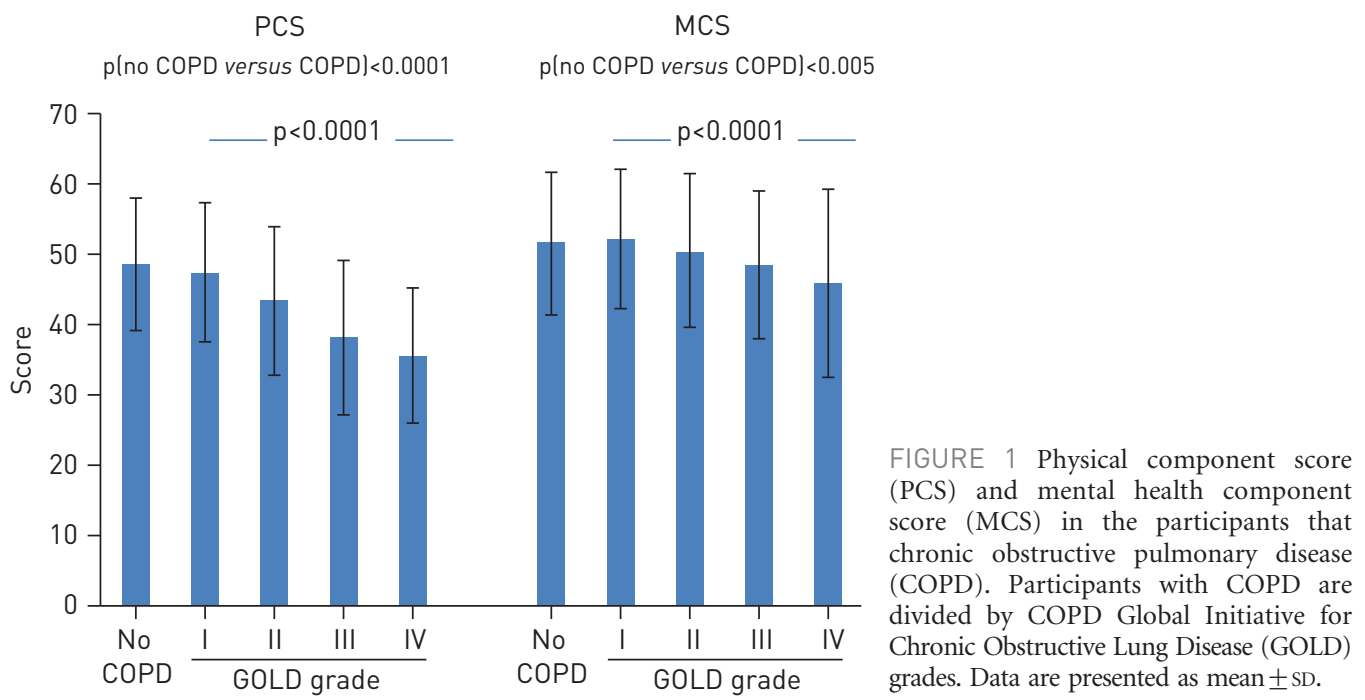

removed from the meta-analysis, the between centre heterogeneity was no longer statistically significant $\left(\mathrm{I}^{2}=18.2\right.$, pheterogeneity $\left.=0.24\right)$.

Redefining COPD using FEV1/FVC ratio $<$ LLN rather than the FEV1/FVC ratio $<0.70$ as the criterion for airflow limitation reduced the number of subjects with COPD from 2269 (18.9\%) to 1520 (12.7\%), but had no effect on the association between COPD grades and health status (table 3 ).

Participants who did not perform a technically satisfactory spirometry had lower PCS ( $45 \pm 11$ versus $48 \pm 10$ units, $\mathrm{p}<0.0001)$ than those that performed a satisfactory spirometry, while there was no difference in MCS (51 units in both groups).

\section{COPD population}

Among subjects with COPD grade 1 or higher, lower FEV1 was independently related to lower PCS but not significantly associated with MCS, after adjusting for the other covariates (table 4). Dyspnoea was the most important determinant of a low PCS and MCS $\left(\mathrm{p}_{\text {trend }}<0.0001\right)$. PCS and MCS were also negatively related to female sex and wheeze. Higher age was associated with lower PCS and higher MCS. In addition a low PCS was related to chronic cough, chronic phlegm, heart disease, diabetes and stroke and a $\mathrm{BMI}>30 \mathrm{~kg} \cdot \mathrm{m}^{-2}$, while a low MCS was related to a $\mathrm{BMI}<20 \mathrm{~kg} \cdot \mathrm{m}^{-2}$ and current smoking (adjusted effect estimate (95\% CI) $-1.49(-2.71--0.28))$.

Among subjects with COPD, 18.2\% were using bronchodilators or ICSs. Adjusting for level of medication use did not change the previously reported associations. Having had at least one exacerbation of COPD within the last 12 months, which was reported by $7.3 \%$ of subjects with COPD, was associated with lower PCS (adjusted estimate (95\% CI) -2.58 (-4.53--0.63)), whereas no significant association was found between MCS and exacerbations. Including exacerbations in the model did not change the associations reported above.

Among subjects with COPD, the relationship between each of these risk factors and health status was not modified by sex.

\section{Discussion}

The main finding in this article is that COPD is an important determinant of health status, but that the effect is stronger on the physical than the mental aspects of health status. COPD severity and current smoking were both independently related to poorer health status. Among people with COPD, physical health status was independently related to lower lung function, the level of dyspnoea and cardiovascular comorbidities, while mental health status was mainly related to the level of dyspnoea.

In our analyses, only subjects with COPD GOLD grade 2 and higher had worse health status that those without COPD. Health status did not differ between subjects with COPD grade 1 and subjects without COPD. As in several other studies, the impact of COPD was larger on the physical than the mental aspects of health status $[5,23,25]$. In accordance with previous studies the negative impact on health status increased with increasing COPD severity [25-27]. The actual SF-12 scores in BOLD participants were similar to those from other population-based studies [5], but the scores were considerably higher, indicating better health status, than in a large European study of patients in primary healthcare setting [26]. 
TABLE 2 Associations between Short Form (SF)-12 physical component score (PCS) and mental health component score (MCS) with chronic obstructive pulmonary disease (COPD) defined as having a post-bronchodilator forced expiratory volume in $1 \mathrm{~s}$ (FEV1)/forced vital capacity (FVC) $<0.70$

PCS SF-12

\section{No COPD \\ COPD (FEV1/FVC <0.70)}

Grade 1

Grade 2

Grade 3

Grade 4

Age per 10 years

Females compared with males

Years of education per year

Smoking history

Never

Ex

Current

Body mass index $\mathrm{kg} \cdot \mathrm{m}^{-2}$

$<20$

$20-25$

$>25-30$

$>30$

\section{Comorbidities}

Heart disease

Hypertension

Diabetes

Stroke
Reference

$$
\begin{gathered}
-0.19(-0.78-0.39) \\
-3.0(-3.6--2.4) \\
-7.8(-8.9--6.7) \\
-11(-14--8.9) \\
-1.2(-1.6--0.8) \\
-2.0(-2.3--1.6) \\
0.23(0.19-0.28)
\end{gathered}
$$

\section{Reference}

$$
-0.39(-0.77--0.01)
$$$$
-1.8(-2.2--1.3)
$$

$-1.0(-1.7--0.37)$

Reference

$-0.54(-0.92--0.15)$

$-2.9(-3.3--2.4)$

$-3.1(-3.6--2.6)$

$-1.2(-1.6--0.85)$

$-2.7(-3.3--2.1)$

$-4.5(-5.4--3.5)$

MCS SF-12

Reference

$0.07(-0.55-0.69$

$-1.4(-2.1--0.77)$

$-3.1(-4.3--2.0)$

$-5.2(-8.1--2.3)$

$0.84(0.67-1.0)$

$-2.2(-2.5--1.8)$

$0.05(0.00-0.10)$

\section{Reference}

-0.38 (-0.79-0.03)

$-1.8(-2.3--1.3)$

$-1.0(-1.8--0.32)$

Reference

$0.05(-0.36-0.46)$

$0.05(-0.43-0.54)$

$-0.78(-1.3--0.26)$

$-0.80(-1.2--0.41)$

$-0.76(-1.4--0.10)$

$-0.23(-1.2-0.77)$

Data are adjusted for the variables in the table and centre are presented as adjusted estimates (95\% confidence interval).

This investigation is unique in the sense that it includes many countries and cultures. Despite this, we found no evidence of geographical differences in the strength of association between physical health status and COPD. As an example, the association between PCS and having COPD stage II or higher was of equal magnitude in high income countries, such as Norway and Canada, to India The weak association between mental health status and COPD was also geographically consistent with the exception of a very strong negative association between COPD grade 2 and higher and MCS in India.

In the present study we used the SF-12 questionnaire. A large number of instruments have been used when assessing health status or health-related quality of life in COPD. These include both disease-specific instruments, such as St George's Respiratory Questionnaire [28], and generic instruments, such as SF-36 [29]. Recently, shorter questionnaires have been used in order to facilitate measurement of health status in

FIGURE 2 Adjusted estimates (95\% confidence interval) of associations of chronic obstructive pulmonary disease (COPD) and comorbidities with the Short Form (SF)-12 physical component score. GOLD: Global Initiative for Chronic Obstructive Lung Disease.

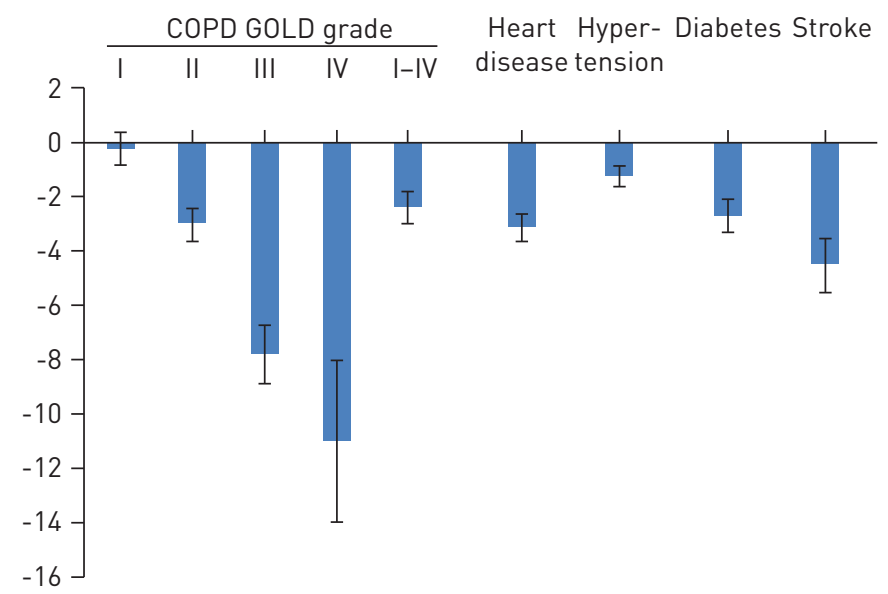




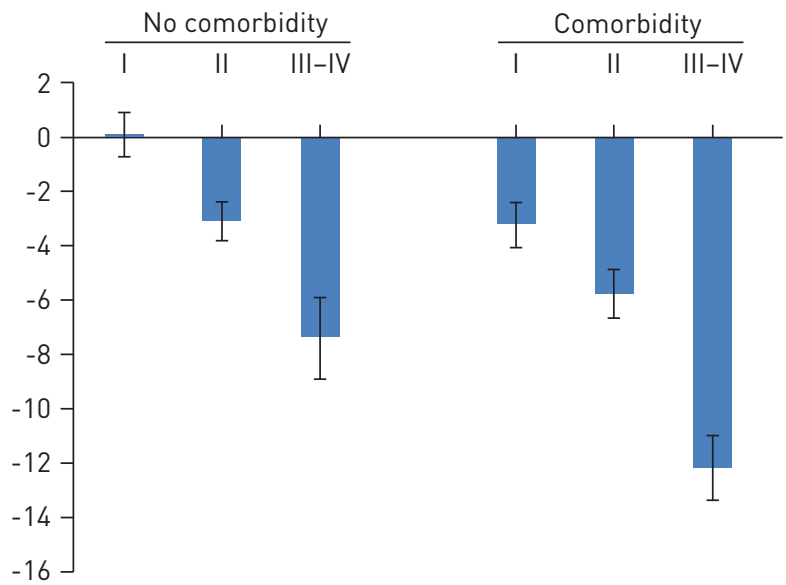

FIGURE 3 Adjusted estimates (95\% confidence interval) of associations of chronic obstructive pulmonary disease Global Initiative for Chronic Obstructive Lung Disease grades in subjects without and with comorbidities (heart disease, hypertension, diabetes and stroke) with the Short Form-12 physical component score.

clinical or epidemiological settings. Examples of shorter health status questionnaires are disease-specific instruments, such as Clinical COPD Questionnaire [30, 31] and the COPD Assessment Test (CAT) [4], and generic instruments, such as EuroQol 5 dimension and SF-12 [32].

The advantage of a generic questionnaire is that it enabled us to compare the effect of different diseases on health status. In this study, the negative influence of self-reported heart disease, diabetes and stroke was of similar magnitude to the effect of COPD grade 2, but considerably less than the effect of COPD grades 3 and 4. It is well known that many patients with COPD have extrapulmonary comorbidities that generate significant healthcare costs $[33,34]$, have a negative effect on rehabilitation outcome [35] and increase the risk of hospitalisations and mortality in COPD patients [36]. Comorbidity may also influence health status in COPD [24]. In the present study, self-reported heart disease had a negative influence on PCS but not MCS. This finding is in accordance with other studies [26, 37]. We also found that diabetes was independently related to lower health status in our participants with COPD. This has been observed in some

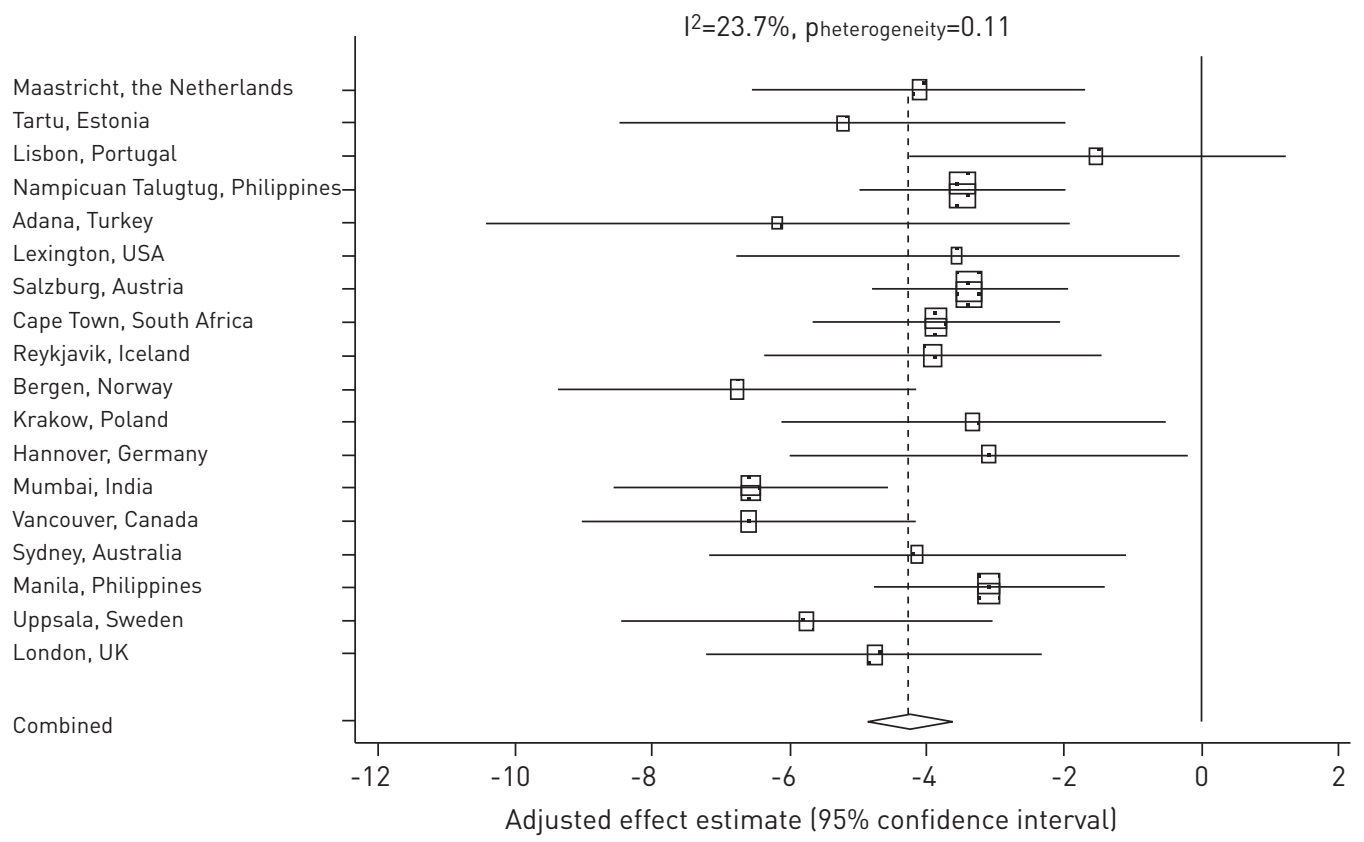

FIGURE 4 Effect estimates and 95\% confidence intervals for the association between the Short Form-12 physical component score and chronic obstructive pulmonary disease (COPD) Global Initiative for Chronic Obstructive Lung Disease grade 2 and higher compared with participants without COPD (adjusted within centre for age, sex, educational level, smoking history, comorbidities and body mass index) with a combined effect estimate (diamond indicates $95 \%$ confidence interval) from the model with centre as the random effect. The size of each square is proportional to the sample size. 


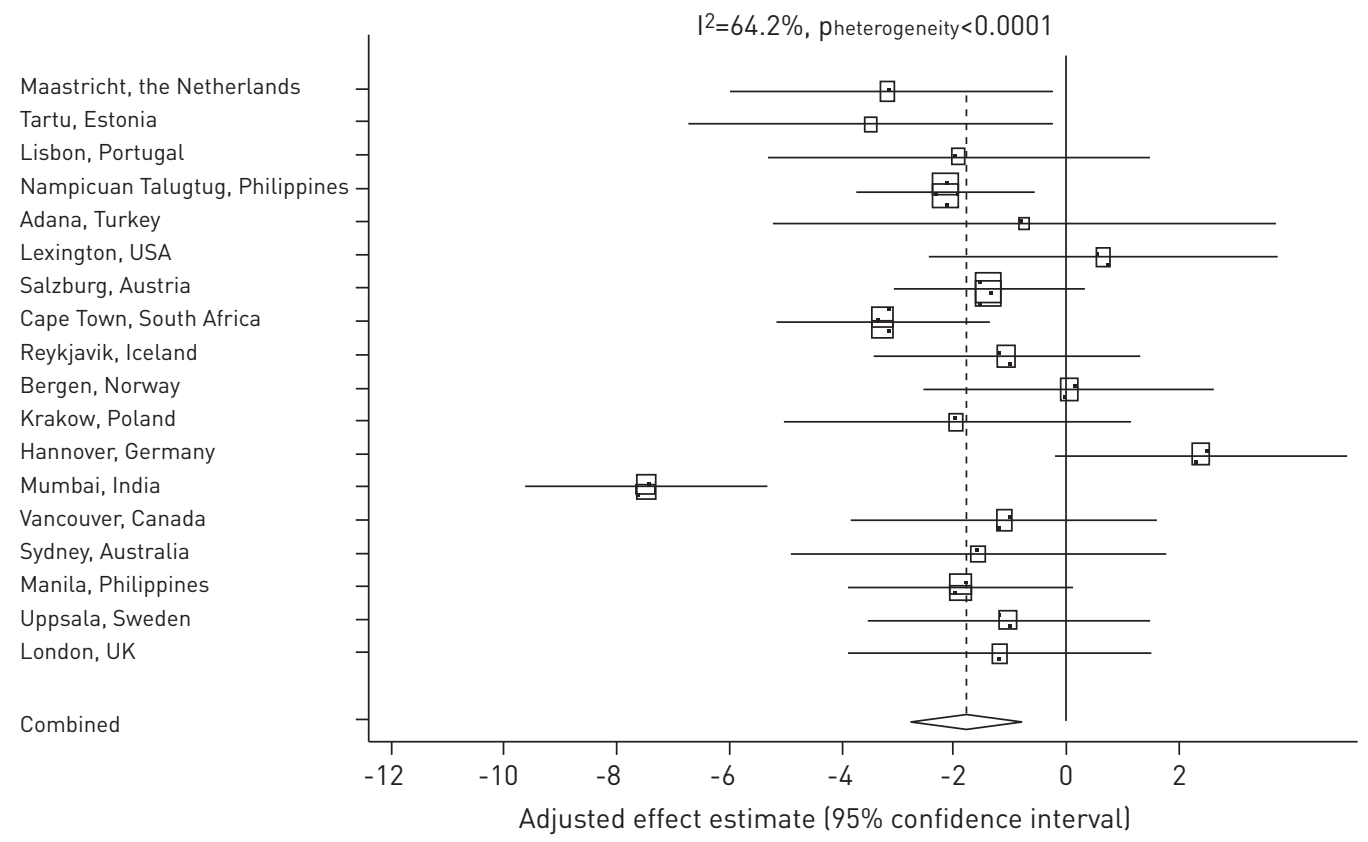

FIGURE 5 Effect estimates and 95\% confidence intervals for the association between the SF-12 mental component score and chronic obstructive pulmonary disease (COPD) Global Initiative for Chronic Obstructive Lung Disease grade 2 and higher compared with participants without COPD (adjusted within centre for age, sex, educational level, smoking history, comorbidities and body mass index) with a combined effect estimate (diamond indicates $95 \%$ confidence interval) from the model with centre as the random effect. The size of each square is proportional to the sample size.

[38], but not all, previous studies [39]. There was an additive effect of COPD severity and comorbidities on impairment of health status in subjects with COPD.

Dyspnoea was independently negatively related to both PCS and MCS in both the present study and in a previous study [40]. Apart from dyspnoea and FEV1, PCS was also related to chronic cough, chronic phlegm and wheeze. In recent years, increased attention has been paid to symptoms associated with COPD. This might be due to the fact that dyspnoea and other respiratory symptoms indicate a worse prognosis in COPD, independent of the level of airflow limitation [41, 42]. Another reason might be that in subjects with COPD, improvement in symptoms may be easier to achieve than improvement in lung function.

In the present study, females with COPD had lower health status than males with COPD. This is a replication of findings from several other studies [5, 40,43]. A low BMI was related to lower MCS and a higher BMI to lower PCS in our investigation. Several other studies have found that both being underweight and being obese are related to decreased health status $[39,44,45]$. In accordance with other studies, higher educational level was associated with better health status [46, 47].

TABLE 3 Associations between Short Form (SF)-12 physical component score (PCS) and mental health component score (MCS) with chronic obstructive pulmonary disease (COPD) defined as having a post-bronchodilator forced expiratory volume in $1 \mathrm{~s}$ (FEV 1 )/forced vital capacity (FVC) predicted below the lower limit of normal (LLN)

PCS SF-12

MCS SF-12

\begin{tabular}{lcc}
\hline No COPD & Reference & Reference \\
COPD (FEV1/FVC <LLN) & & $-0.28(-1.13-0.56)$ \\
Grade 1 & $-0.26(-1.05-0.53)$ & $-1.2(-1.9--0.44)$ \\
Grade 2 & $-3.2(-3.9--2.5)$ & $-2.9(-4.1--1.7)$ \\
Grade 3 & $-7.9(-9.0--6.8)$ & $-5.1(-8.0--2.2)$ \\
Grade 4 & $-12(-14--8.8)$ & . \\
\hline
\end{tabular}

Data are presented as adjusted estimates (95\% confidence interval). Estimates are adjusted for age, sex, educational level, smoking history, body mass index, cardiovascular diseases, diabetes and centre. 
TABLE 4 Associations between Short Form (SF)-12 physical component score (PCS) and mental health component score (MCS) in subjects with chronic obstructive pulmonary disease (COPD)

PCS SF-12

FEV1 per $10 \%$ predicted
Dyspnoea
Grade 0
Grade 1
Grade 2
Grade 3
Grade 4
Age per 10 years

Females compared with males

Symptoms

Chronic cough

Chronic phlegm

Wheeze

Body mass index $\mathrm{kg} \cdot \mathrm{m}^{-2}$

$<20$

20-25

$>25-30$

$>30$

Comorbidities

Heart disease

Hypertension

Diabetes

Stroke
$0.89(0.68-1.1)$

Reference

$-1.9(-3.0--0.79)$

$-4.1(-5.4--2.8)$

$-5.5(-7.2--3.9)$

$-8.6(-11--6.6)$

$-1.3(-1.7--0.96)$

$-1.4(-2.2--0.57)$

$-1.4(-2.8--0.07)$

$-1.9(-3.3--0.53)$

$-1.1(-2.0--0.25)$

$0.09(-1.3-1.5)$

Reference

$0.06(-1.0-0.88)$

$-1.4(-2.5--0.19)$

$-1.5(-2.6--0.46)$

$-0.23(-1.1-0.46)$

$-2.0(-3.6--0.53)$

$-3.0(-5.1--1.0)$
MCS SF-12

$-0.07(-0.29-0.16)$

Reference

$-0.59(-1.8-0.64)$

$-1.3(-2.8-0.15)$

$-3.2(-5.1--1.4)$

$-6.2(-8.4--4.0)$

$0.75(0.34-1.2)$

$-2.2(-3.1--1.3)$

$-0.48(-2.0-1.0)$

$-1.4(-3.0-0.17)$

$-1.5(-2.5--0.46)$

$-2.5(-4.1--1.0)$

Reference

$0.78(-0.43-1.6)$

$0.64(-0.68-2.0)$

$-0.12(-1.3-1.1)$

$-0.51(-1.5-0.46)$

$-0.69(-2.4-1.0)$

$0.82(-1.4-3.1)$

Data are presented as adjusted estimates (95\% confidence interval). Estimates are adjusted for the variables in the table, smoking history, educational level and centre. FEV1: forced expiratory volume in $1 \mathrm{~s}$.

The BOLD study is one of several large epidemiological studies that have examined health status in people with COPD. The Epidemiologic Study of COPD in Spain (EPI-SCAN) has highlighted the importance of impaired health status in people with undiagnosed COPD [48]. The Latin American Project for the Investigation of Obstructive Lung Disease (PLATINO) has focused on sex differences and has shown that health status was lower in females than males [5]. The Canadian Obstructive Lung Disease prevalence study has been used to validate the CAT. Components of CAT can be of value for identifying subjects with previously undiagnosed COPD [49].

Strengths of this study include the large sample size and the use of a standardised method of data collection, together with a high level of quality control that increases the internal validity of the analyses [12, 13]. Also, BOLD includes subjects from a large number of countries, which increases the external validity of our findings. The use of questionnaires in different languages may introduce problems. However, in BOLD, the translations of the original questionnaires have been validated. Another possible limitation is that we did not collect data on depression, which has been shown to be related to health status in patients with COPD [50]. As the protocol did not include the CAT, we were not able to classify the subjects according to the newly developed GOLD groups A-D [18]. Finally, lack of a disease-specific health status questionnaire and the fact that the information on comorbidities was self-reported should be taken into account when interpreting our findings.

We confirm that COPD is related to worse health status and that the effect on the physical aspects of health status is stronger than the effect on the mental aspects. In severe COPD, the degree of impairment in health status is greater than the effect seen in people with self-reported cardiovascular diseases and diabetes. In subjects with COPD, health status is related to low lung function, dyspnoea, symptoms and comorbidities.

\section{Acknowledgements}

The BOLD Investigators would like to thank the BOLD Executive Committee (Nadia AitKhaled (Algier, Algeria), Sonia Buist (Portland, OR, USA), Peter Burney (London, UK), Rain Jõgi (Tartu, Estonia), Bernet Kato (London, UK), Tod Lee (Chicago, IL, USA), David Mannino (Lexington, KY, USA), Ana Menezes (Pelotas, Brazil), Sundeep Salvi (Pune, India) and William Vollmer (Portland, OR, USA)); the BOLD Co-ordinating Center staff (Sonia Buist, Suzanne Gillespie and William Vollmer (Portland, OR, USA); Peter Burney (London, UK), Anamika Jithoo (Cape Town, South Africa), Louisa 
Gnatiuc, Richard Hooper, Bernet Kato, Sonia Coton and Hadia Azhar (London, UK); members of the Pulmonary Function Reading Center (Paul Enright (The University of Arizona, Tucson, AZ, USA) and Anamika Jithoo), and the individual BOLD site investigators and their key staff for their generous help and advice throughout the project.

BOLD wishes to acknowledge the contributions of Georg Harnoncourt of the ndd Corporation (ndd Medizintechnik AG, Zurich, Switzerland) and Paul Enright (The University of Arizona, Tucson, AZ, USA) for their assistance with spirometry training and quality control during the study.

Field Centres were as follows: Ali Kocabaş (principal investigator (PI)), Attila Hancioglu, Ismail Hanta, Sedat Kuleci, Ahmet Sinan Turkyilmaz, Sema Umut and Turgay Unalan (Cukurova University School of Medicine, Department of Chest Diseases, Adana, Turkey); Michael Studnicka (PI), Torkil Dawes, Bernd Lamprecht and Lea Schirhofer (Paracelsus Medical University, Department of Pulmonary Medicine, Salzburg, Austria); Eric Bateman (PI), Anamika Jithoo (PI), Desiree Adams, Edward Barnes, Jasper Freeman, Anton Hayes, Sipho Hlengwa, Christine Johannisen, Mariana Koopman, Innocentia Louw, Ina Ludick, Alta Olckers, Johanna Ryck and Janita Storbeck (University of Cape Town Lung Institute, Cape Town, South Africa); Thorarinn Gislason (PI), Bryndis Benedikdtsdottir, Kristin Jörundsdottir, Lovisa Gudmundsdottir, Sigrun Gudmundsdottir and Gunnar Gundmundsson (Landspitali University Hospital, Dept. of Allergy, Respiratory Medicine and Sleep, Reykjavik, Iceland); Ewa Nizankowska-Mogilnicka (PI), Jakub Frey, Rafal Harat, Filip Mejza, Pawel Nastalek, Andrzej Pajak, Wojciech Skucha, Andrzej Szczeklik and Magda Twardowska (Division of Pulmonary Diseases, Department of Medicine, Jagiellonian University School of Medicine, Cracow, Poland); Tobias Welte (PI), Isabelle Bodemann, Henning Geldmacher and Alexandra Schweda-Linow (Hannover Medical School, Hannover, Germany); Amund Gulsvik (PI), Tina Endresen and Lene Svendsen (Department of Thoracic Medicine, Institute of Medicine, University of Bergen, Bergen, Norway); Wan C. Tan (PI) and Wen Wang (iCapture Center for Cardiovascular and Pulmonary Research, University of British Columbia, Vancouver, BC, Canada); David M. Mannino (PI), John Cain, Rebecca Copeland, Dana Hazen and Jennifer Methvin (University of Kentucky, Lexington, KY, USA); Renato B. Dantes (PI), Lourdes Amarillo, Lakan U. Berratio, Lenora C. Fernandez, Norberto A. Francisco, Gerard S. Garcia, Teresita S. de Guia, Luisito F. Idolor, Sullian S. Naval, Thessa Reyes, Camilo C. Roa Jr., Ma. Flordeliza Sanchez and Leander P. Simpao (Philippine College of Chest Physicians, Manila, Philippines); Christine Jenkins (PI), Guy Marks (PI), Tessa Bird, Paola Espinel, Kate Hardaker and Brett Toelle (Woolcock Institute of Medical Research, Sydney, Australia); Peter GJ Burney (PI), Caron Amor, James Potts, Michael Tumilty and Fiona McLean (National Heart and Lung Institute, Imperial College, London, UK); E.F.M. Wouters and G.J. Wesseling (Maastricht University Medical Center, Maastricht, the Netherlands); Cristina Bárbara (PI), Fátima Rodrigues, Hermínia Dias, João Cardoso, João Almeida, Maria João Matos, Paula Simão, Moutinho Santos and Reis Ferreira (The Portuguese Society of Pneumology, Lisbon, Portugal); Christer Janson (PI), Inga Sif Olafsdottir, Katarina Nisser, Ulrike Spetz-Nyström, Gunilla Hägg and Gun-Marie Lund (Dept of Medical Sciences: Respiratory Medicine and Allergology, Uppsala University, Sweden); Rain Jõgi (PI), Hendrik Laja, Katrin Ulst, Vappu Zobel and Toomas-Julius Lill (Lung Clinic, Tartu University Hospital, Tartu, Estonia); Rohini Chowgule (PI) Vasant Shetye, Jonelle Raphael, Rosel Almeda, Mahesh Tawde, Rafiq Tadvi, Sunil Katkar, Milind Kadam, Rupesh Dhanawade and Umesh Ghurup (Indian Institute of Environmental Medicine, Mumbai, India); and Luisito F. Idolor (PI), Teresita S. de Guia, Norberto A. Francisco, Camilo C. Roa, Fernando G. Ayuyao, Cecil Z.Tady, Daniel T. Tan, Sylvia Banal-Yang, Vincent M. Balanag Jr., Maria Teresita N. Reyes and Renato B. Dantes (Lung Centre of the Philippines, Philippine General Hospital, Nampicuan and Talugtug, Philippines).

Additional local support for BOLD clinical sites was provided by: Turkish Thoracic Society, Boehringer-Ingelheim and Pfizer (Adana, Turkey); Altana, Astra-Zeneca, Boehringer-Ingelheim, GlaxoSmithKline, Merck Sharpe and Dohme, Novartis, Salzburger Gebietskrankenkasse and Salzburg Local Government (Salzburg, Austria); Research for International Tobacco Control, the International Development Research Centre, the South African Medical Research Council, the South African Thoracic Society GlaxoSmithKline Pulmonary Research Fellowship, and the University of Cape Town Lung Institute (Cape Town, South Africa); and Landspítali-University Hospital-Scientific Fund, GlaxoSmithKline Iceland and AstraZeneca Iceland (Reykjavik, Iceland); GlaxoSmithKline Pharmaceuticals, Polpharma, Ivax Pharma Poland, AstraZeneca Pharma Poland, ZF Altana Pharma, Pliva Kraków, Adamed, Novartis Poland, Linde Gaz Polska, Lek Polska, Tarchomińskie Zakłady Farmaceutyczne Polfa, Starostwo Proszowice, Skanska, Zasada, Agencja Mienia Wojskowego w Krakowie, Telekomunikacja Polska, Biernacki, Biogran, Amplus Bucki, Skrzydlewski, Sotwin and Agroplon (Cracow, Poland); Boehringer-Ingelheim and Pfizer Germany (Hannover, Germany); the Norwegian Ministry of Health's Foundation for Clinical Research, and Haukeland University Hospital's Medical Research Foundation for Thoracic Medicine (Bergen, Norway); AstraZeneca, Boehringer-Ingelheim, Pfizer and GlaxoSmithKline (Vancouver, Canada); Marty Driesler Cancer Project (Lexington, KY, USA); Altana, Boehringer Ingelheim (Phil), GlaxoSmithKline, Pfizer, Philippine College of Chest Physicians, Philippine College of Physicians and United Laboratories (Phil) (Manila, Philippines); Air Liquide Healthcare P/L, AstraZeneca P/L, Boehringer Ingelheim P/L, GlaxoSmithKline Australia P/L and Pfizer Australia P/L (Sydney, Australia); Dept of Health Policy Research Programme and Clement Clarke International (London, UK); Boehringer Ingelheim and Pfizer (Lisbon, Portugal); Swedish Heart and Lung Foundation, The Swedish Association against Heart and Lung Diseases and Glaxo Smith Kline (Uppsala, Sweden); GlaxoSmithKline, Astra Zeneca and Eesti Teadusfond (Estonian Science Foundation) (Tartu, Estonia); AstraZeneca and CIRO HORN (Maastricht, the Netherlands); Foundation for Environmental Medicine, Kasturba Hospital and Volkart Foundation (Mumbai, India); and Philippines College of Physicians, Philippines College of Chest Physicians, AstraZeneca, Boehringer Ingelheim, GlaxoSmithKline, Orient Euro Pharma, Otsuka Pharma and United laboratories Phillipines (Nampicuan and Talugtug, Philippines).

\section{References}

1 Lopez AD, Mathers CD, Ezzati M, et al. Global and regional burden of disease and risk factors, 2001: systematic analysis of population health data. Lancet 2006; 367: 1747-1757.

2 Gudmundsson G, Gislason T, Janson C, et al. Depression, anxiety and health status after hospitalisation for COPD: a multicentre study in the Nordic countries. Respir Med 2006; 100: 87-93.

3 Almagro P, Calbo E, Ochoa de Echagüen A, et al. Mortality after hospitalization for COPD. Chest 2002; 121: $1441-1448$. 
Jones PW, Brusselle G, Dal Negro RW, et al. Properties of the COPD assessment test in a cross-sectional European study. Eur Respir J 2011; 38: 29-35.

5 Lopez Varela MV, Montes de Oca M, Halbert RJ, et al. Sex-related differences in COPD in five Latin American cities: the PLATINO study. Eur Respir J 2010; 36: 1034-1041.

$6 \mathrm{Xu} \mathrm{W}$, Collet JP, Shapiro S, et al. Negative impacts of unreported COPD exacerbations on health-related quality of life at 1 year. Eur Respir J 2010; 35: 1022-1030.

7 Esteban C, Quintana JM, Aburto M, et al. Impact of changes in physical activity on health-related quality of life among patients with chronic obstructive pulmonary disease. Eur Respir J 2010; 36: 292-300.

8 Burtin C, Saey D, Saglam M, et al. Effectiveness of exercise training in patients with COPD: the role of muscle fatigue. Eur Respir J 2012; 40: 338-344.

9 Burtin C, Decramer M, Gosselink R, et al. Rehabilitation and acute exacerbations. Eur Respir J 2011; 38 : $702-712$.

10 Szafranski W, Cukier A, Ramirez A, et al. Efficacy and safety of budesonide/formoterol in the management of chronic obstructive pulmonary disease. Eur Respir J 2003; 21: 74-81.

11 Troosters T, Celli B, Lystig T, et al. Tiotropium as a first maintenance drug in COPD: secondary analysis of the UPLIFT trial. Eur Respir J 2010; 36: 65-73.

12 Buist AS, McBurnie MA, Vollmer WM, et al. International variation in the prevalence of COPD (the BOLD Study): a population-based prevalence study. Lancet 2007; 370: 741-750.

13 Buist AS, Vollmer WM, Sullivan SD, et al. The Burden of Obstructive Lung Disease Initiative (BOLD): rationale and design. COPD 2005; 2: 277-283.

14 Hooper R, Burney P, Vollmer WM, et al. Risk factors for COPD spirometrically defined from the lower limit of normal in the BOLD project. Eur Respir J 2012; 39: 1343-1353.

15 Nielsen R, Johannessen A, Benediktsdottir B, et al. Present and future costs of COPD in Iceland and Norway: results from the BOLD study. Eur Respir J 2009; 34: 850-857.

16 Miller MR, Hankinson J, Brusasco V, et al. Standardisation of spirometry. Eur Respir J 2005; 26: 319-338.

17 Hankinson JL, Odencrantz JR, Fedan KB. Spirometric reference values from a sample of the general U.S. population. Am J Respir Crit Care Med 1999; 159: 179-187.

18 Vestbo J, Hurd SS, Agustí AG, et al. Global strategy for the diagnosis, management and prevention of chronic obstructive pulmonary disease: GOLD executive summary. Am J Respir Crit Care Med 2013; 187: $347-365$.

19 Gandek B, Ware JE, Aaronson NK, et al. Cross-validation of item selection and scoring for the SF-12 Health Survey in nine countries: results from the IQOLA Project. International Quality of Life Assessment. J Clin Epidemiol 1998; 51: 1171-1178.

20 Fletcher CM, Elmes PC, Fairbairn AS, et al. The significance of respiratory symptoms and the diagnosis of chronic bronchitis in a working population. Br Med J 1959; 2: 257-266.

DerSimonian R, Laird N. Meta-analysis in clinical trials. Control Clin Trials 1986; 7: 177-188.

Higgins JP, Thompson SG, Deeks JJ, et al. Measuring inconsistency in meta-analyses. BMJ 2003; 327: 557-560.

Methvin JN, Mannino DM, Casey BR. COPD prevalence in southeastern Kentucky: the burden of lung disease study. Chest 2009; 135: 102-107.

24 van Manen JG, Bindels PJ, Dekker FW, et al. The influence of COPD on health-related quality of life independent of the influence of comorbidity. J Clin Epidemiol 2003; 56: 1177-1184.

25 Ståhl E, Lindberg A, Jansson SA, et al. Health-related quality of life is related to COPD disease severity. Health Qual Life Outcomes 2005; 3: 56.

26 Jones PW, Brusselle G, Dal Negro RW, et al. Health-related quality of life in patients by COPD severity within primary care in Europe. Respir Med 2011; 105: 57-66.

27 Voll-Aanerud M, Eagan TM, Wentzel-Larsen T, et al. Respiratory symptoms, COPD severity, and health related quality of life in a general population sample. Respir Med 2008; 102: 399-406.

28 Jones PW, Quirk FH, Baveystock CM, et al. A self-complete measure of health status for chronic airflow limitation. The St. George's Respiratory Questionnaire. Am Rev Respir Dis 1992; 145: 1321-1327.

29 Domingo-Salvany A, Lamarca R, Ferrer M, et al. Health-related quality of life and mortality in male patients with chronic obstructive pulmonary disease. Am J Respir Crit Care Med 2002; 166: 680-685.

30 Ställberg B, Nokela M, Ehrs PO, et al. Validation of the clinical COPD Questionnaire (CCQ) in primary care. Health Qual Life Outcomes 2009; 7: 26.

31 Jones PW, Harding G, Berry P, et al. Development and first validation of the COPD Assessment Test. Eur Respir J 2009; 34: 648-654.

32 Menn P, Weber N, Holle R. Health-related quality of life in patients with severe COPD hospitalized for exacerbations - comparing EQ-5D, SF-12 and SGRQ. Health Qual Life Outcomes 2010; 8: 39.

33 Simon-Tuval T, Scharf SM, Maimon N, et al. Determinants of elevated healthcare utilization in patients with COPD. Respir Res 2011; 12: 7.

34 Nielsen R, Johannessen A, Omenaas ER, et al. Excessive costs of COPD in ever-smokers. A longitudinal community study. Respir Med 2011; 105: 485-493.

35 Crisafulli E, Costi S, Luppi F, et al. Role of comorbidities in a cohort of patients with COPD undergoing pulmonary rehabilitation. Thorax 2008; 63: 487-492.

36 Mannino DM, Thorn D, Swensen A, et al. Prevalence and outcomes of diabetes, hypertension and cardiovascular disease in COPD. Eur Respir J 2008; 32: 962-969.

37 de Miguel-Díez J, Carrasco-Garrido P, Rejas-Gutierrez J, et al. The influence of heart disease on characteristics, quality of life, use of health resources, and costs of COPD in primary care settings. BMC Cardiovasc Disord 2010; 10: 8 .

38 Jimenez-Garcia R, de Miguel-Díez J, Rejas-Gutierrez J, et al. Health, treatment and health care resources consumption profile among Spanish adults with diabetes and chronic obstructive pulmonary disease. Prim Care Diabetes 2009; 3: 141-148.

39 Sundh J, Stallberg B, Lisspers K, et al. Co-morbidity, body mass index and quality of life in COPD using the Clinical COPD Questionnaire. COPD 2011; 8: 173-181.

40 Rodríguez-González Moro JM, Izquierdo JL, Antón E, et al. Health-related quality of life in outpatient women with COPD in daily practice: the MUVICE Spanish study. Respir Med 2009; 103: 1303-1312. 
41 Nishimura K, Izumi T, Tsukino M, et al. Dyspnea is a better predictor of 5-year survival than airway obstruction in patients with COPD. Chest 2002; 121: 1434-1440.

42 de Marco R, Accordini S, Antò JM, et al. Long-term outcomes in mild/moderate chronic obstructive pulmonary disease in the European community respiratory health survey. Am J Respir Crit Care Med 2009; 180: 956-963.

43 Carrasco-Garrido P, de Miguel-Díez J, Rejas-Gutierrez J, et al. Characteristics of chronic obstructive pulmonary disease in Spain from a gender perspective. BMC Pulm Med 2009; 9: 2.

44 Katsura H, Yamada K, Kida K. Both generic and disease specific health-related quality of life are deteriorated in patients with underweight COPD. Respir Med 2005; 99: 624-630.

45 Søltoft F, Hammer M, Kragh N. The association of body mass index and health-related quality of life in the general population: data from the 2003 Health Survey of England. Qual Life Res 2009; 18: 1293-1299.

46 Wahl AK, Rustøen T, Hanestad BR, et al. Quality of life in the general Norwegian population, measured by the Quality of Life Scale (QOLS-N). Qual Life Res 2004; 13: 1001-1009.

47 Wahl DG, Bounameaux H, de Moerloose P, et al. Prophylactic antithrombotic therapy for patients with systemic lupus erythematosus with or without antiphospholipid antibodies: do the benefits outweigh the risks? A decision analysis. Arch Intern Med 2000; 160: 2042-2048.

48 Miravitlles M, Soriano JB, García-Río F, et al. Prevalence of COPD in Spain: impact of undiagnosed COPD on quality of life and daily life activities. Thorax 2009; 64: 863-868.

49 Raghavan N, Lam YM, Webb KA, et al. Components of the COPD Assessment Test (CAT) associated with a diagnosis of COPD in a random population sample. COPD 2012; 9: 175-183.

50 Gudmundsson G, Gislason T, Lindberg E, et al. Mortality in COPD patients discharged from hospital: the role of treatment and co-morbidity. Respir Res 2006; 7: 109. 